\title{
Unexpected Complication of R-CHOP Chemotherapy: Rapidly Progressive Bronchiolitis Obliterans Syndrome
}

\author{
$\underline{\text { Kenji Nozaki }}{ }^{1}$, Sachiko Ezoe ${ }^{1}$, Masanari Hamaguchi $^{2}$, Kazuhito Tsutsumi $^{1}$, Shinsuke Kusakabe ${ }^{1}$, Yoichiro Morikawa ${ }^{1}$, Jiro Fujita $^{1}$, \\ Kentaro Fukushima ${ }^{1}$, Tetsuo Maeda ${ }^{1}$, Hirohiko Shibayama ${ }^{1}$, Atsushi Kumanogo ${ }^{2}$, Yuzuru Kanakura ${ }^{1}$ \\ ${ }^{1}$ Department of Hematology and Oncology, Osaka University Graduate School of Medicine, Osaka, Japan \\ ${ }^{2}$ Department of Respiratory Medicine and Clinical Immunology, Graduate School of Medicine, Osaka University, Osaka, Japan
}

Received: 28/08/2019

Accepted: $10 / 09 / 2019$

Published: $28 / 10 / 2019$

\begin{abstract}
How to cite this article: Nozaki K, Ezoe S, Hamaguchi M, Tsutumi K Kusakabe S, Morikawa Y, Fujita J, Fukushima K, Maeda T, Shimayama H, Kumanogo At, Kanakura Y. Unexpected complication of R-CHOP chemoterapy: rapidly progressive bronchiolitis obliterans syndrome. EJCRIM 2019;6:
\end{abstract} doi:10.12890/2019_001266.

Conflicts of Interests: The Authors declare that there are no competing interest

This article is licensed under a Commons Attribution Non-Commercial 4.0 License

\section{ABSTRACT}

Background: Bronchiolitis obliterans syndrome (BOS) is the term used for the progressive obliteration of small airways before the patient has had a confirmatory lung biopsy. It is also recognized as a transplant-related complication. There have been no reports of BOS during initial standard chemotherapy.

Case presentation: A 50-year-old woman with newly diagnosed follicular lymphoma grade 2, stage 3A, presented with hypoxia and progressive dyspnoea after the fifth cycle of R-CHOP. High-resolution computed tomography showed air trapping enhanced at the end-expiratory phase. Pulmonary function testing revealed severe obstructive and restrictive failure without bronchodilator response. We diagnosed BOS based on current criteria and treated the patient with glucocorticoids and cyclosporin. She was discharged home on oxygen therapy. However, soon after discharge, her respiratory symptoms deteriorated and she was hospitalized in a palliative care unit. She died of respiratory failure within a year of symptom onset.

Conclusions: This is the first case report to describe rapidly progressive BOS in a patient undergoing R-CHOP treatment, which strongly suggests the condition was caused by the chemotherapy. Although a pathological diagnosis was not obtained, the clinical diagnosis of BOS was important so that the patient could receive appropriate treatment and palliative care based on the prognosis of this incurable condition.

\section{LEARNING POINTS}

- R-CHOP chemotherapy may cause rapidly progressive bronchiolitis obliterans syndrome (BOS).

- When it is difficult to obtain a pathological diagnosis, a clinical diagnosis of BOS is important for early intervention and appropriate palliative care.

\section{KEYWORDS}

Bronchiolitis obliterans syndrome, follicular lymphoma, R-CHOP, chemotherapy- related

\section{CASE DESCRIPTION}

A 50-year-old Japanese woman was admitted to the authors' hospital for further investigation of hypoxia and progressive dyspnoea. She had been newly diagnosed with follicular lymphoma (FL) grade 2, stage 3A, and had started standard dose R-CHOP (rituximab, cyclophosphamide, doxorubicin, vincristine and prednisolone) chemotherapy 4 months previously. She had developed non-productive cough and dyspnoea on exertion after the fifth cycle without chest radiographic or echocardiographic abnormality. On the sixth (final) cycle, she presented with hypoxia and deteriorating symptoms. 
The patient's medical history was unremarkable, except for FL. She had no history of allergy. She had never smoked and had not been exposed to dust or toxic chemicals. She did not regularly take any prescription or non-prescription medicine.

She was afebrile and her respiratory rate was 20 breaths/min. Oxygen saturation was $89 \%$ on room air and $98 \%$ on $3 \mathrm{l} / \mathrm{min}$ oxygen, but had been normal ( $98 \%$ on room air) just before chemotherapy. Arterial blood gas analysis revealed hypoxaemia, while other laboratory data were unremarkable (Table 1). Breath sounds were decreased in the bilateral lower lung fields.

\begin{tabular}{|c|c|c|c|c|c|c|c|c|}
\hline \multicolumn{2}{|c|}{ Complete blood count } & \multicolumn{2}{|c|}{ Biochemistry } & \multicolumn{2}{|c|}{ Immunology } & \multicolumn{3}{|c|}{$\begin{array}{l}\text { Arterial blood gas analysis } \\
021.5 \mathrm{I} / \mathrm{min}\end{array}$} \\
\hline WBC & $10,040 / \mu l$ & $\mathrm{Na}$ & $143 \mathrm{mEq} / \mathrm{l}$ & $\lg G$ & $598 \mathrm{mg} / \mathrm{dl}$ & $P h$ & \multicolumn{2}{|l|}{7.434} \\
\hline Neutrophil & $86 \%$ & K & $4.1 \mathrm{mEq} / \mathrm{l}$ & $\operatorname{IgA}$ & $67 \mathrm{mg} / \mathrm{dl}$ & $\mathrm{PO} 2$ & \multicolumn{2}{|c|}{$95.6 \mathrm{mmHg}$} \\
\hline Lymphocyte & $6.2 \%$ & $\mathrm{Cl}$ & $102 \mathrm{mEq} / \mathrm{l}$ & $\lg M$ & $43 \mathrm{mg} / \mathrm{dl}$ & PCO2 & \multicolumn{2}{|c|}{$46.3 \mathrm{mmHg}$} \\
\hline Monocyte & $6.8 \%$ & UN & $10 \mathrm{mg} / \mathrm{dl}$ & C3 & $69.6 \mathrm{U} / \mathrm{ml}$ & $\mathrm{HCO} 3$ & \multicolumn{2}{|l|}{$31 \mathrm{mmol} / \mathrm{l}$} \\
\hline Eosinophil & $0.7 \%$ & Cre & $0.58 \mathrm{mg} / \mathrm{dl}$ & C4 & $45 \mathrm{mg} / \mathrm{dl}$ & $\mathrm{SO} 2$ & \multicolumn{2}{|l|}{$97.4 \%$} \\
\hline Basophil & $0.3 \%$ & AST & $24 \mathrm{U} / \mathrm{I}$ & $\mathrm{CH} 5 \mathrm{O}$ & $69.6 \mathrm{U} / \mathrm{ml}$ & \multicolumn{3}{|c|}{ Pulmonary function test } \\
\hline$R B C$ & $4.08 \times 10^{4} / \mu l$ & ALT & $23 \mathrm{U} / \mathrm{I}$ & $\begin{array}{l}\text { Anti nuclear } \\
\text { antibody }\end{array}$ & $<40 x$ & & $\begin{array}{l}\text { Actual } \\
\text { value }\end{array}$ & $\begin{array}{l}\text { Predicted } \\
\text { value }\end{array}$ \\
\hline $\mathrm{Hb}$ & $11.5 \mathrm{~g} / \mathrm{dL}$ & yGTP & $20 \mathrm{U} / \mathrm{I}$ & Anti AchR antibody & Negative & FVC & 1.241 & 43.9 \\
\hline $\mathrm{Ht}$ & $37.7 \%$ & LDH & $248 \mathrm{U} / \mathrm{I}$ & C-ANCA & Negative & FEV 1.0 & 0.441 & 18.7 \\
\hline Plt & $56.4 \times 10^{4} / \mu l$ & CRP & $0.33 \mathrm{mg} / \mathrm{dl}$ & P-ANCA & Negative & FEV $1.0 \%$ & $35.5 \%$ & \\
\hline \multicolumn{2}{|c|}{ Coagulation } & $T P$ & $6.5 \mathrm{~g} / \mathrm{dl}$ & $\begin{array}{l}\text { Anti demosglein-1 } \\
\text { antibody }\end{array}$ & Negative & FEV 1.0/VC & $16.7 \%$ & \\
\hline PT-INR & 1.03 & Alb & $3.4 \mathrm{~g} / \mathrm{dl}$ & $\begin{array}{l}\text { Anti demosglein-1 } \\
\text { antibody }\end{array}$ & Negative & & & \\
\hline APTT & $27 s$ & CK & $73 \mathrm{U} / \mathrm{I}$ & Anti BP180 antibody & Negative & & & \\
\hline Fib & $539 \mathrm{mg} / \mathrm{dl}$ & KL-6 & $256 \mathrm{U} / \mathrm{ml}$ & C7-HRP & Negative & & & \\
\hline D-Dimer & $0.71 \mu \mathrm{g} / \mathrm{ml}$ & sIL-2R & $401 \mathrm{U} / \mathrm{ml}$ & B-D Glucan & Negative & & aboratory & \\
\hline
\end{tabular}

Chest radiography revealed a dropped heart and a hyperinflated lung which developed after symptom onset (Fig. 1). CT of the whole body showed bulky intraperitoneal lymph nodes reduced in size, with other previously enlarged lesions now normalized (Fig. 2). Highresolution CT (HRCT) of the chest revealed bronchial dilatation and a mosaic pattern consisting of high- and low-density areas that represented bronchiolar air trapping, which was enhanced at the end-expiratory phase, although CT of the chest before chemotherapy had not demonstrated abnormal findings (Fig. 3). Pulmonary function testing (PFT) revealed severe obstructive and restrictive failure (forced expiratory volume in $1 \mathrm{~s}, 19 \%$ of predicted; forced vital capacity, $43.9 \%$ of predicted) without bronchodilator response (Fig. 4).

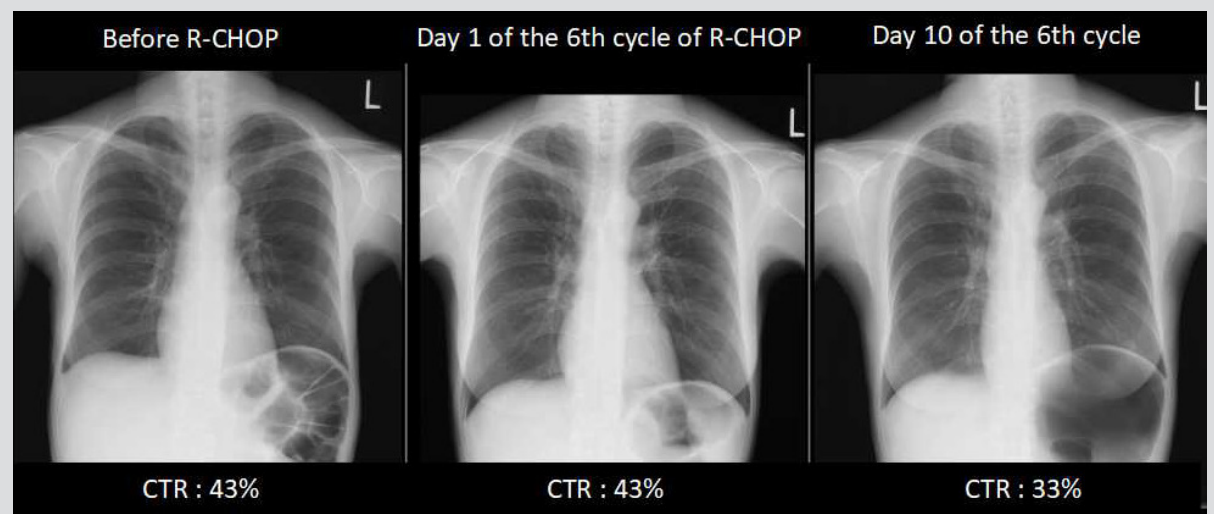

Figure 1. Chest radiographs showing a dropped heart and lung hyperinflation which appeared soon after symptom onset. CTR: cardiothoracic ratio 


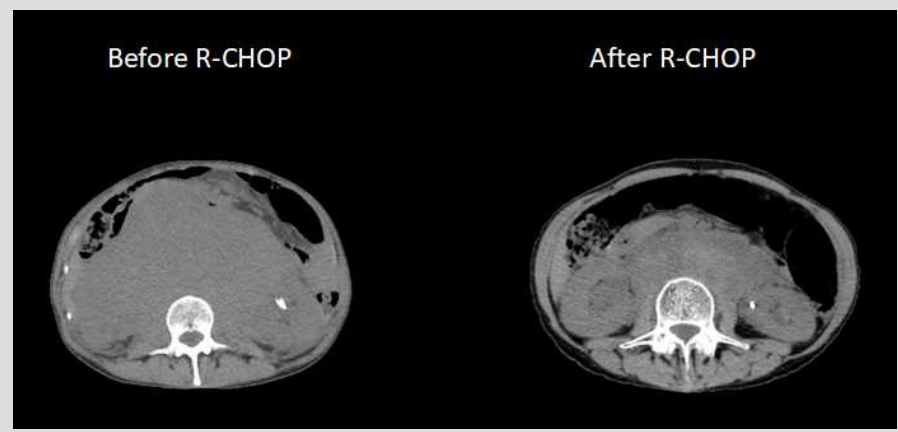

Figure 2. CT of the abdomen showing intraperitoneal lymph nodes still present but reduced in size

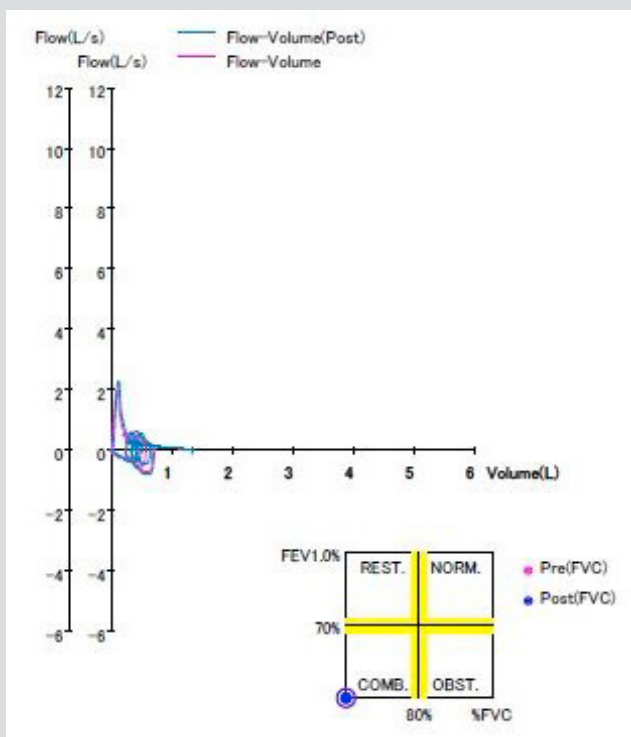

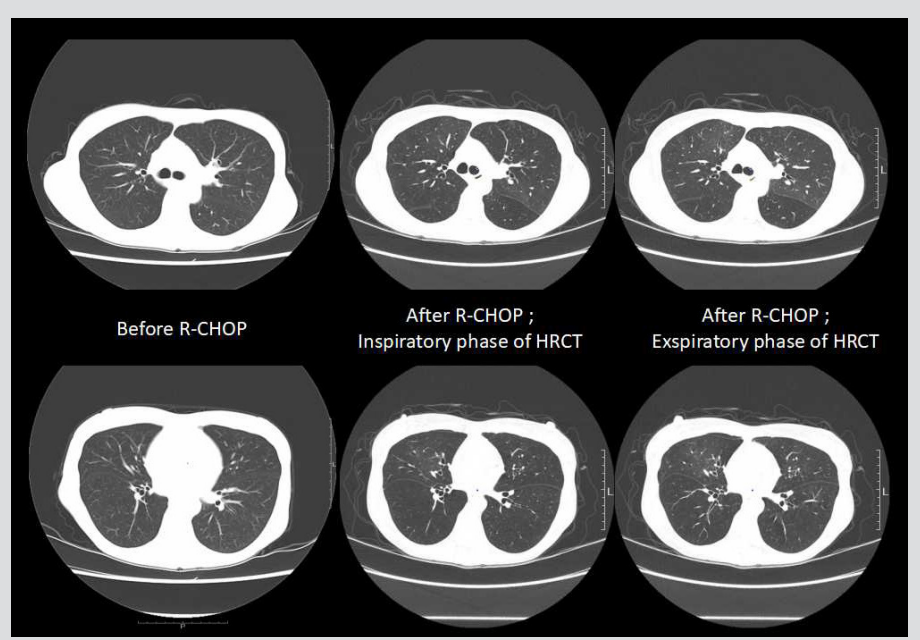

Figure 3. CT of the chest showing a mosaic pattern of air trapping enhanced at the expiratory phase (chest CT before chemotherapy was normal)

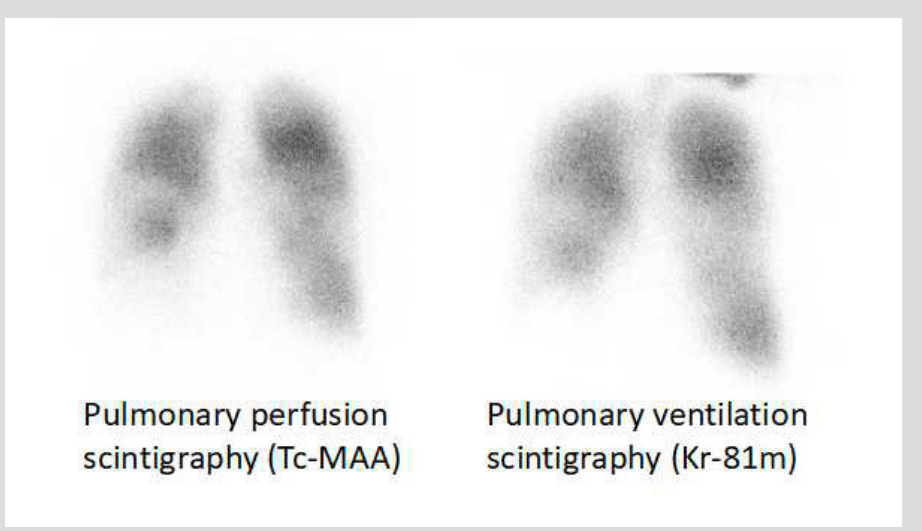

Figure 4. Pulmonary function testing with a bronchodilator revealing severe obstructive and restrictive failure without bronchodilator response

Figure 5. Pulmonary ventilation and perfusion scintigraphy revealing a mosaic pattern of radio-isotope uptake decrease without ventilation-perfusion mismatch

The patient was certain her PFT results had been normal several years previously. Pulmonary ventilation and perfusion scintigraphy revealed a mosaic pattern of radio-isotope uptake decrease without ventilation-perfusion mismatch (Fig. 5).

$\mathrm{BO}$ was strongly suspected clinically and these results met the current criteria for BOS ${ }^{[1]}$. A lung biopsy for the diagnosis of BO was not performed due to the patient's poor performance status and the risk of serious respiratory injury being caused by the surgical procedure. The patient was diagnosed with BOS after other differential diseases had been excluded.

Steroid pulse therapy (methylprednisolone $1 \mathrm{~g} /$ day) was administered for 3 days, followed by prednisolone $1 \mathrm{mg} / \mathrm{kg}$. The patient was also treated with low-dose oral azithromycin and inhalation of tiotropium. However, she developed respiratory failure on exertion and required positive pressure ventilation support twice during a 1-month period. Steroid pulse therapy was repeated and cyclosporine was added. Her respiratory condition stabilised and she was discharged home on oxygen therapy. However, soon after discharge, her respiratory symptoms deteriorated and she was hospitalized in a palliative care unit. The patient died of respiratory failure within a year of symptom onset.

\section{DISCUSSION}

The clinical course of this patient shows that she developed BOS rapidly during R-CHOP therapy with no association with transplantation or any other known cause(s), which strongly suggests that chemotherapy can cause BOS. 
BO is recognized as a manifestation of chronic graft-versus-host disease in patients who have undergone HSCT ${ }^{[2,3]}$. However, some agents and diseases can also cause lung injury that results in BO. Examples include inhalation of nitrogen oxides or diacetyl, Sauropus androgynus consumption, respiratory infection and autoimmune diseases, such as rheumatic diseases and paraneoplastic pemphigus (PNP) ${ }^{[4-11]}$. BO is rarely caused by drugs, with reports limited to gold and penicillamine ${ }^{[12,13]}$. A direct causal relationship with rituximab, cyclophosphamide, doxorubicin and vincristine has not been described.

There was a previous case report of BO after rituximab-containing chemotherapy. A 63-year-old woman with FL who was treated with six cycles of R-CHOP, developed progressive airflow obstruction 3 years after the last treatment and was diagnosed with BO 2 years later ${ }^{[14]}$. Our patient rapidly developed BOS during R-CHOP chemotherapy and quickly deteriorated, which was totally different from the case described above. Chest imaging with radiography, CT and PFT indicated her symptoms presented after initiation of chemotherapy. There were no other definitive causes and concomitant idiopathic BOS was unlikely. PNP-related BO in patients with malignant lymphoma has been reported ${ }^{[7]}$. However, our patient never exhibited evidence of PNP physically or serologically (Table 1). Therefore, our case strongly suggests that the occurrence of BOS was related to therapy, which was also different from the case above.

The diagnosis of $\mathrm{BO}$ usually requires an open or thoracoscopic lung biopsy, although this is often inadequate for diagnosis due to patchy distribution of the lesion. Because lung biopsy is often difficult for patients with pulmonary failure, it is now considered that in a highprobability clinical setting, such as a known predisposing inhalational exposure or transplantation, the combination of airflow limitation on PFT and typical HRCT findings, such as expiratory air trapping and bronchial wall thickening, may be sufficient to make the diagnosis. The International Society for Heart and Lung Transplantation proposed the term 'BOS' as the clinical diagnosis for post-transplanted patients with the aim of early diagnosis and intervention ${ }^{[15,16]}$. The diagnosis of BOS requires the careful exclusion of other differential diagnoses. The clinical manifestations in our case did not follow a typical pattern for asthma or COPD because the patient was a non-smoker and airflow limitation was irreversible. Other diseases, such as interstitial pneumonia, organizing pneumonia, hypersensitivity pneumonitis, sarcoidosis and pulmonary embolism, were excluded due to absence of typical findings. Because our patient met the current criteria for BOS (1, 2, 3 and $4 \mathrm{~b})^{[1]}$, we diagnosed her with BOS to allow early intervention and treatment. R-CHOP is standard chemotherapy for de novo malignant lymphoma of B-cell origin, including FL. Therefore, in similarly treated non-transplant patients, BOS should be included in the differential diagnosis for new respiratory symptoms. Although BOS in some patients is progressive and fatal, despite all therapies, clinical diagnosis enables us to provide appropriate treatment and palliative care.

\section{REFERENCES}

1. Williams KM. How I treat bronchiolitis obliterans syndrome after hematopoietic stem cell transplantation. Blood 2017;129(4):448-455.

2. Williams KM, Chien JW, Gladwin MT, Pavletic SZ. Bronchiolitis obliterans after allogeneic hematopoietic stem cell transplantation. JAMA 2009;302(3):306-314.

3. Jagasia MH, Greinix HT, Arora M, et al. National Institutes of Health Consensus Development Project on Criteria for Clinical Trials in Chronic Graft-versus-Host Disease: I. The 2014 Diagnosis and Staging Working Group report. Biol Blood Marrow Transplant 2015;21(3):389-401.e1.

4. Hendrick DJ. "Popcorn worker's lung" in Britain in a man making potato crisp flavouring. Thorax 2008;63(3):267-268.

5. Hsiue TR, Guo YL, Chen KW, Chen CW, Lee CH, Chang HY. Dose-response relationship and irreversible obstructive ventilatory defect in patients with consumption of Sauropus androgynus. Chest 1998;113(1):71-76.

6. Ghanei M, Tazelaar HD, Chilosi M, et al. An international collaborative pathologic study of surgical lung biopsies from mustard gas-exposed patients. Respir Med 2008;102(6):825830.

7. Nousari HC, Deterding R, Wojtczack H, et al. The mechanism of respiratory failure in paraneoplastic pemphigus. New Engl J Med 1999;340(18):1406-1410.

8. Perez T, Remy-Jardin M, Cortet B. Airways involvement in rheumatoid arthritis: clinical, functional, and HRCT findings. Am J Resp Crit Care Med 1998;157(5 Pt 1):1658-1665.

9. Becroft DM. Bronchiolitis obliterans, bronchiectasis, and other sequelae of adenovirus type 21 infection in young children. J Clin Pathol 1971;24(1):72-82.

10. Hardy KA, Schidlow DV, Zaeri N. Obliterative bronchiolitis in children. Chest 1988;93(3):460-466.

11. Devouassoux G, Cottin V, Liote H, et al. Characterisation of severe obliterative bronchiolitis in rheumatoid arthritis. Eur Respir J 2009;33(5):1053-1061.

12. Lyle WH. D-Penicillamine and fatal obliterative bronchiolitis. Br Med J 1977;1(6053):105.

13. Schwartzman KJ, Bowie DM, Yeadon C, Fraser R, Sutton ED, Levy RD. Constrictive bronchiolitis obliterans following gold therapy for psoriatic arthritis. Eur Resp J 1995;8(12):2191-2193.

14. Nishihara T, Nakano H, Nogami H, et al. A 63-year-old woman with progressive dyspnea after remission of lymphoma. Chest 2017;151(3):e57-e62.

15. Estenne M, Maurer JR, Boehler A, et al. Bronchiolitis obliterans syndrome 2001: an update of the diagnostic criteria. J Heart Lung Transplant 2002;21(3):297-310.

16. Cooper JD, Billingham M, Egan T, et al. A working formulation for the standardization of nomenclature and for clinical staging of chronic dysfunction in lung allografts. $J$ Heart Lung Transplant 1993;12(5):713-716. 